\title{
Magnetic Properties of Hard/Soft-Stacked Perpendicular Media Having Very Thin Soft Layers with a High Saturation Magnetization
}

\author{
Y. Inaba, T. Shimatsu, S. Watanabe*, O. Kitakami**, S. Okamoto**, H. Muraoka, H. Aoi, and Y. Nakamura \\ Research Institute of Electrical Communication, Tohoku Univ., Katahira 2-1-1, Aoba-ku, Sendai 980-8577, Japan \\ ${ }^{*}$ Fuji Electric Advanced Technology Co., Ltd., Tsukama 4-18-1, Matsumoto 390-0821, Japan \\ ${ }^{* *}$ Institute of Multidisciplinary Research for Advanced Materials, Tohoku Univ., Katahira 2-1-1, Aoba-ku, Sendai 980-8577, Japan
}

The magnetic properties and recording performance of hard/soft-stacked media consisting of a magnetically hard layer $(9-10 \mathrm{~nm})$ underneath a very thin soft layer $(2 \mathrm{~nm})$ with a large saturation magnetization were investigated. Magnetic energy calculations revealed that reducing the strength of the interfacial exchange coupling between the hard and soft layers reduces the remanence coercivity, $H_{\mathrm{r}}$. Moreover, an increase in the saturation magnetization of the soft layer $<M_{\mathrm{s}}$ soft $>$ significantly enhances the $H_{\mathrm{r}}$ reduction. It is theoretically predicted that the grain volume of hard $(10 \mathrm{~nm}) / \mathrm{soft}(2 \mathrm{~nm})$ stacked media having $<M_{\mathrm{s}}$ soft $>$ of $1000 \mathrm{emu} / \mathrm{cm}^{3}$ could be reduced to about $1 / 3$ that of conventional media whilst maintaining good recording writability and thermal stability. An experimental study of stacked media revealed that the magnetization reversal mechanism changed systematically as a function of the strength of the interfacial exchange coupling, as predicted theoretically. The $H_{\mathrm{r}}$ reduction on adjusting the interfacial coupling reached $22 \%$ of that of media consisting of directly coupled hard/soft grains. It was successfully demonstrated that hard/soft-stacked media having thin soft layers with a large $<M_{\mathrm{s}}$ soft $>$ showed better recording writability without degradation of $S N_{\mathrm{m}} R$, recording resolution, or thermal stability.

Key words: hard/soft-stacked perpendicular recording media, thermal stability, saturation recording

\section{高飽和磁化の薄いソフト層を有する Hard/Soft スタック垂直媒体の 磁気特性と記録再生特性}

\author{
稲葉祐樹・島津武仁・渡辺貞幸*・北上＼cjkstart修** 岡本＼cjkstart聡**・村岡裕明・青井 基・中村慶久 \\ 東北大学電気通信研究所, 仙台市青葉区片平 2 丁目 1-1 (厂980-8577) \\ *富士電機アドバンストテクノロジー株式会社，松本市筑摩 4丁目 18-1（テ390-0821） \\ **東北大学多元物質科学研究所, 仙台市青葉区片平 2 丁目 1-1（广980-8577）
}

\section{1. はじめに}

我々はこれまでに，ハード層に種々のソフト層を付与したグラ ニュラ構造を有するスタック媒体について検討を行ってきている 1),2).この媒体は熱安定性を大きく損なうことなく保磁力を低減し, 飽和記録特性を向上させることが可能であることを理論，実験の 両面から明らかにしている.さらに，ソフト層の飽和磁化を大き くすることでゼーマン項が増加し, 保磁力が大きく減少するため, これらの効果は異方性の大きな材料を媒体として使いこなすのに 非常に有効である. しかし現行の成膜プロセスでは，ソフト層の 膜厚を厚くしすぎると結晶粒の分離度が劣化してしまうため, ソ フト層は数 nm 以下の領域で用いる必要がある3).

一方，Victora らは，界面の結合力を制御することて熱安定性を 維持しながらスイッチング磁界をさらに下げることが可能である ことを理論的に示している4).ただし, 報告されているモデル計算 では，ソフト層の磁化回転を促進するためにソフト層を厚く設定 しているが，上述したように粒子の分離度を保ったままソフト層 を厚く成長させることは容易ではない．

そこで本論文では，薄いソフト層を有するグラニュラ型のスタ ック媒体について，まず，界面の結合力，および，飽和磁化を変 化させた場合のエネルギ一計算を行い，薄く，かつ高飽和磁化の ソフト層を用いることで, どの程度の高密度化が期待できるのか を検討した. さらに，上記の結果を踏まえ，薄く且つ高飽和磁化
のソフト層を有するグラニュラ媒体を作製し, 界面の結合力の強 さと磁気特性及び記録再生特性の関係を明らかにし，同媒体の性 能と課題について検証したので報告する.

\section{Hard/Soft スタック粒子のエネルギ一計算}

\section{1 計算条件}

Fig. 1 に示すように，磁気異方性の大きなハード材料の 上に，ソフト材料を載せた粒子を想定した。このとき，系 全体の磁気エネルギー $E$ は, 次のように表すことができる.

$$
E=E_{\text {anisotropy }}+E_{\text {zeeman }}+E_{\text {exchange }}
$$

ここで， $E_{\text {anisotropy }}, E_{\text {zeeman }}, E_{\text {exchange }}$ は，それぞれ，次に 示すように，ハード，ソフト各材料の磁気異方性エネルギ 一，ゼーマンエネルギー，および界面の結合力に起因する エネルギーであり，次のように表すことができる．

$$
\begin{gathered}
E_{\text {anisotropy }}=K_{\text {u hard }}\left(\mathrm{S} \delta_{\text {hard }}\right) \sin ^{2} \theta_{\text {hard }} \\
+K_{\text {u soft }}\left(\mathrm{S}_{\text {soft }}\right) \sin ^{2} \theta_{\text {soft }}
\end{gathered}
$$




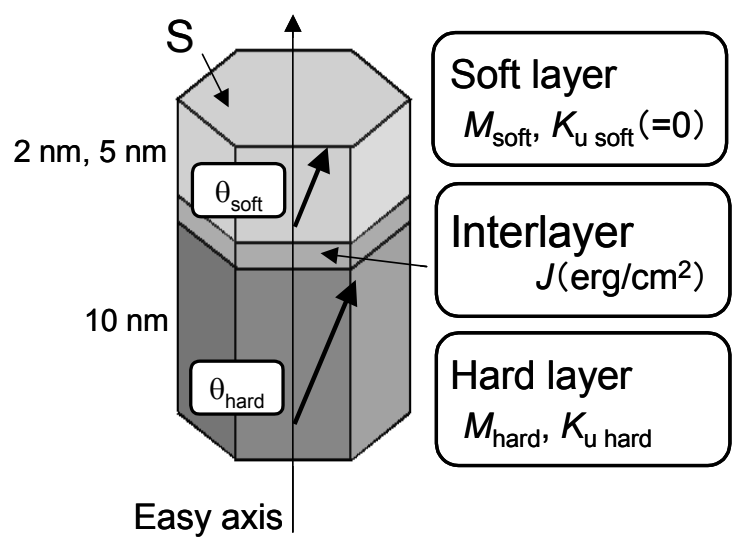

Fig. 1 Schematic view of stacked grains consisting of a soft layer, a hardlayer, and an interlayer.

ここで， $\theta$ は容易軸と磁化のなす角度， $\phi$ は容易軸と印加 磁界のなす角度, $S$ は粒の断面積, $\delta$ は膜厚, $M_{\mathrm{s}}$ は飽和磁 化, $K_{\mathrm{u}}$ は一軸磁気異方性エネルギー, Jは界面結合エネル ギー $\left(\mathrm{erg} / \mathrm{cm}^{2}\right), H$ は外部印加磁界をそれぞれ表す。外部磁 界の印加方向は，磁化容易軸方向とした。 なお，ハード， ソフト各層における值には，それぞれ hard, soft の添え字 をつけて表記した。

ハード層の膜厚は $10 \mathrm{~nm}$ で一定とし，ソフト層の膜厚は $5 \mathrm{~nm}$ および $2 \mathrm{~nm}$ の 2 種類について検討した.粒径は $7 \mathrm{~nm}$ としたが，粒子体積を変化させた計算では粒径を変化させ ている.ソフト層の $K_{\mathrm{u}}$ は 0 とし，スタック粒子の充填率 は現行の媒体とほぼ同じである $70 \%$ とした，充填率を考慮 した膜平均の $K_{\mathrm{u}}$ 及び $M_{\mathrm{s}}$ の值は， $<K_{\mathrm{u}}>$ 及び $<M_{\mathrm{s}}>$ と表記し た。また，界面結合エネルギーの分散は考慮していない.

(1)式に示した磁気エネルギーを $H$ の関数として計算し, スイッチング磁界 $H_{\mathrm{sw}}$ を求めた，粒子の集合体では，保磁 力近傍では膜平均の磁化が 0 となるため, $H_{\mathrm{sw}}$ の計算にお いて反磁界の影響は無視した。また， $H=4 \pi<M_{\mathrm{s}}>$ の反磁界 が印加された状態におけるエネルギーポテンシャル曲線か ら, 飽和残留磁化状態におけるエネルギー障壁 $\Delta E$ を求めた.

ここで，記録過程において媒体の磁化曲線が飽和する飽 和磁界， $H_{\mathrm{s}}$ を下記のように定義した。

$$
H_{\mathrm{s}}=0.9 \times H_{\mathrm{sw}}+(4 \pi / 3)<M_{\mathrm{s}}>/ \alpha
$$

ここでは粒子の c 軸分散を考慮し， $H_{\mathrm{sw}}$ を 0.9 倍したも のを実効的なスイッチング磁界とした. 磁化曲線の傾き, $\alpha$, は 1.0 としたが, 記録過程では, 裏打ち層と主磁極とで挟 まれる効果により，媒体の反磁界係数が $1 / 3$ 倍 5 ), 6)に低減 すると仮定した。この $1 / 3$ は, 記録時の反磁界の減衰率と しては大きめの仮定であるが，一方で，媒体に仮定した $\alpha=1.0$ は，想定している媒体の膜厚および層構成から考え ると7)小さめな值であり， $H_{\mathrm{s}}$ の評価の上でバランスを取っ ている．計算では，ヘッドの最大磁界が $16 \mathrm{kOe}$ であると 仮定して飽和記録条件を $H_{\mathrm{s}}=16 \mathrm{kOe}$ とした.

また，熱安定性の議論では， $\Delta E / k T=60$ を熱安定性が確 保できる指標とした。

\section{2 界面結合カに対するエネルギ一変化}

Fig. 2 には, $H_{\mathrm{sw}}$ と $\Delta E$ の值を, 界面結合力の強さ $J$ に対 して示した. $\Delta E$ は熱エネルギー $k T$ で規格化して示してあ る.ここでは, 一例として, ソフト層膜厚が $5 \mathrm{~nm}$, ハード 層，ソフト層の $<M_{\mathrm{s}}>$ がいずれも $400 \mathrm{emu} / \mathrm{cm}^{3}$ とした場合 のスタック媒体の結果が示してある。また，眓中には各領 域における磁化反転様式を模式図で示した。

結合力が強い領域ではソフト，ハード両層の磁化は一斉 反転するが，結合力を弱めることでソフト層が先に反転を 始め，スイッチング磁界が低下寸ることがわかる．またこ の時，エネルギー障壁はほとんど変化しない，さらに結合 力を低下させると，ソフト層が先に反転を終えてしまい， その後ハード層が反転する，いわゆるスピンフロップ状態 が出現し，スイッチング磁界は急激に増加する.

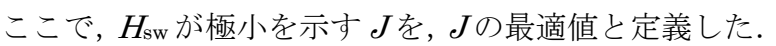
計算では, ハード層及びソフト層の膜厚, 物性值等を変化

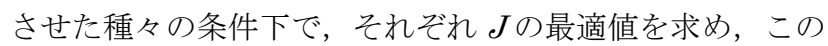
$J$ の最適值における $H_{\mathrm{sw}}$ および $\Delta E$ の值を求めた. これ以降 に示す $H_{\mathrm{sw}}$ および $\Delta E$ の值は, 特に断らない限り, この $J$ の最適值における值である.

\section{3 スタック媒体と単層媒体の比較}

まず，ハード層とソフト層の飽和磁化が同じ場合につい て，単層媒体との比較を行った．Fig. 3 には，ソフト層の 厚みを $5 \mathrm{~nm}$ とし，式(3)に示した飽和記録条件を満足する ハード層の $K_{\mathrm{u}}$ を，八ード層及びソフト層の $M_{\mathrm{s}}$ に対して示 した．図では，充填率を考慮した膜平均の值である $<K_{\mathrm{u}}>$ と $<M_{\mathrm{s}}>$ の関係を示してある. 図中には, スタック媒体の総膜 厚と同じ膜厚 $15 \mathrm{~nm}$ のハード層のみの媒体（単層媒体と表 現）の結果も示してある.いずれの媒体でも，全体の $\left\langle M_{\mathrm{s}}>\right.$ が大きくなるほど式(3)を満たす $<K_{\mathrm{u}}>$ 值は増加するが, スタ

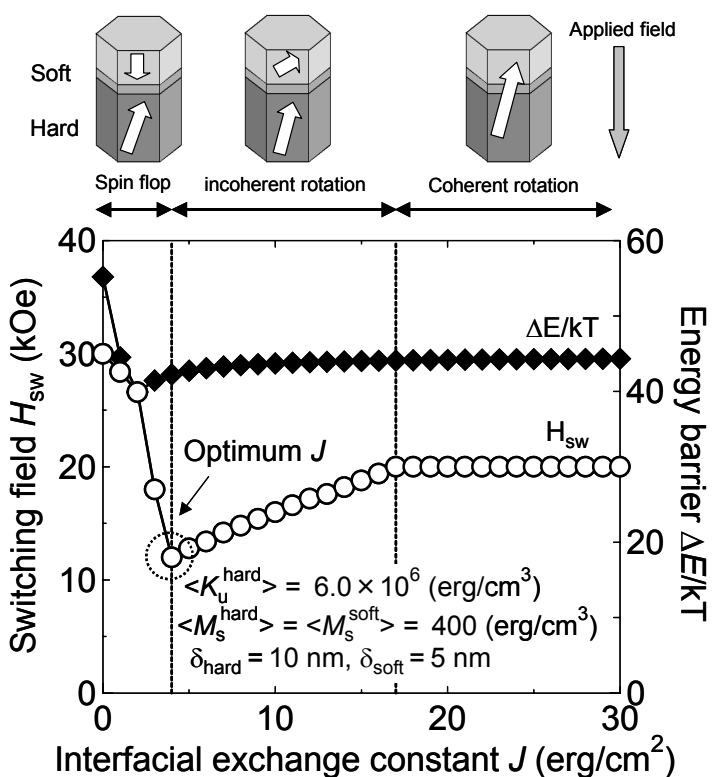

Fig. 2 Exchange constant dependence for the switching field and energy barrier of stacked grain. 


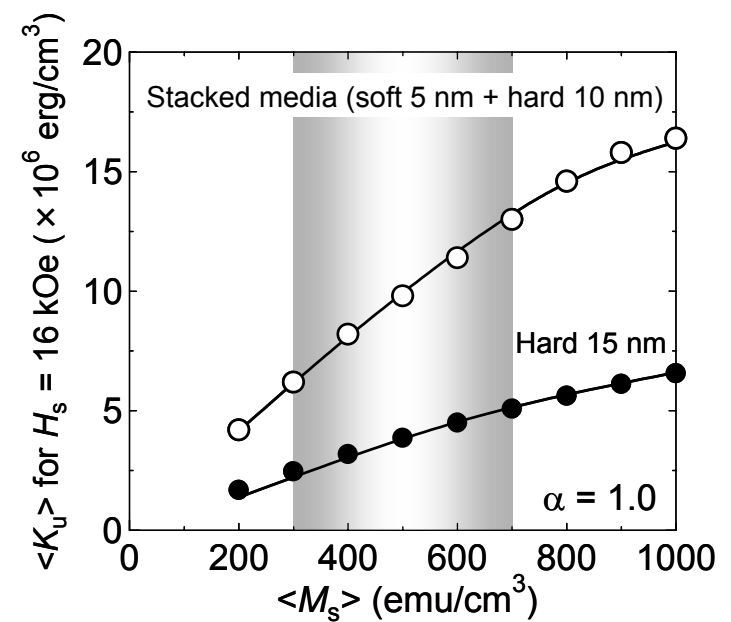

Fig. 3 Change in anisotropy energy for $H_{\mathrm{s}}=16 \mathrm{kOe}$ as a function of the saturation magnetization.

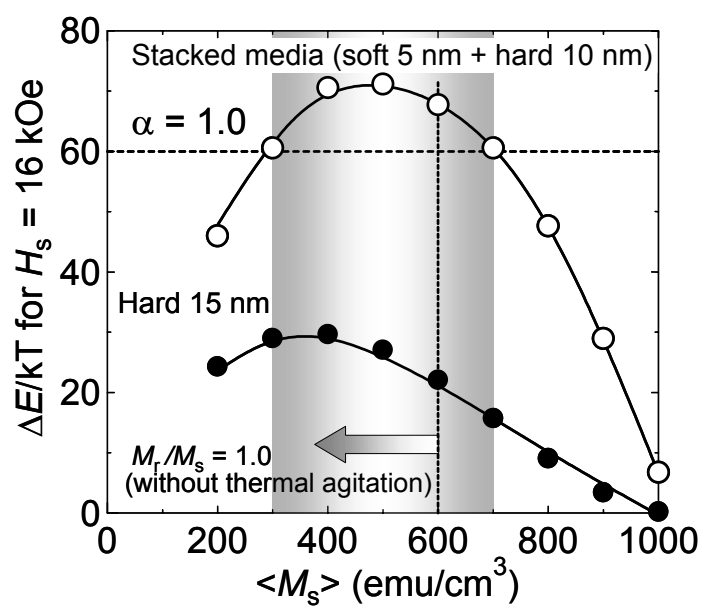

Fig. 4 Change in energy barrier for $H_{\mathrm{s}}=16 \mathrm{kOe}$ as a function of the saturation magnetization.

ック媒体では, 同じ膜厚の単層媒体に比べて 2 倍以上大き な $<K_{\mathrm{u}}>$ の材料を使うことが可能となる.

Fig. 4 には, これらの媒体の $\Delta E / k T$ の值を示した. いず れの媒体でも, Fig. 3 に示した $<K_{\mathrm{u}}>$ 值の増加により $\Delta E / k T$ が増加するが, $<M_{\mathrm{s}}>$ が大きくなり過ぎると, 膜の反磁界の 増加により $\Delta E / k T$ は逆に低下寸る. スタック媒体の $\Delta E / k T$ は, 単層媒体よりも 2 倍以上大きく, $<M_{\mathrm{s}}>$ が $300 \sim 700$ $\mathrm{emu} / \mathrm{cm}^{3}$ の領域で, 実用的な熱安定性を確保できると考え られる $\Delta E / k T=60$ の值を超えている. ただし, 熱擾乱によ る保磁力の低減を考慮しない場合でも, 磁化曲線の角型比 を 1 に維持するためには， $<M_{\mathrm{s}}>$ は $600 \mathrm{emu} / \mathrm{cm}^{3}$ 以下であ る必要がある.

ここで, 十分な熱安定性が得られる場合には, 粒子の体 積を減少させることで高密度化が実現できることになる.

Fig. 5 には飽和記録条件と $\Delta E l k T=60$ の両方を満足する粒 子体積 $<V_{\text {grain }}>$ を示した. スタック媒体の $<V_{\text {grain }}>$ は, 単層 媒体の $1 / 2$ 以下であり, $<M_{\mathrm{s}}>$ が大きいほど両者の差が大き い. スタック媒体において $<V_{\text {grain }}>$ が最も小さくなる $<M_{\mathrm{s}}>$ は 400 500 $\mathrm{emu} / \mathrm{cm}^{3}$ であり, この時, $<K_{\mathrm{u}}>=8 \sim 10 \times 10^{6}$ $\mathrm{erg} / \mathrm{cm}^{3}, J=5 \sim 6 \mathrm{erg} / \mathrm{cm}^{2}$ に対応する. また, この< $M_{\mathrm{s}}>$ 領域 におけるスタック媒体の< $V_{\text {grain }}>$ は約 $700 \mathrm{~nm}^{3}$ であり, 単 層媒体の< $V_{\text {grain }}>02.4$ 分の 1 まで低下できることになる. なお，熱擾乱による残留保磁力の低下を考えると， $<M_{\mathrm{s}}>=400 \sim 500 \mathrm{emu} / \mathrm{cm}^{3}$ の領域は, VSM の時間スケール で角型比 1 が得られる臨界的な $<M_{\mathrm{s}}>$ 領域に相当すると考 えられる。これは， $H_{\mathrm{s}}$ および角型比の議論の上で最も厳し い条件である $\alpha=1.0$ を想定して議論しているためであり, 実際には $\alpha$ が 1.0 以上の大きさになることを考慮すると, VSM の時間スケールで角型比 1.0 は満足できると考えら れる.

\section{4 ソフト層の飽和磁化の増大効果}

Fig. 6 には, ハード層の $<M_{\mathrm{s}}>$ を $400 \mathrm{emu} / \mathrm{cm}^{3}$ に固定し, ソフト層の $<M_{\mathrm{s}}>$ のみを変化させた場合の $<V_{\mathrm{grain}}>$ を, ソフ 卜層の $<M_{\mathrm{s}}>$ 值 $\left(<M_{\mathrm{s}}{ }^{\mathrm{soft}}>\right)$ に対して示した。計算ではハー ド層とソフト層の界面における磁束の不連続性の影響は無 視している. 図中には, ソフト層の厚みが $5 \mathrm{~nm}$ と $2 \mathrm{~nm}$ の

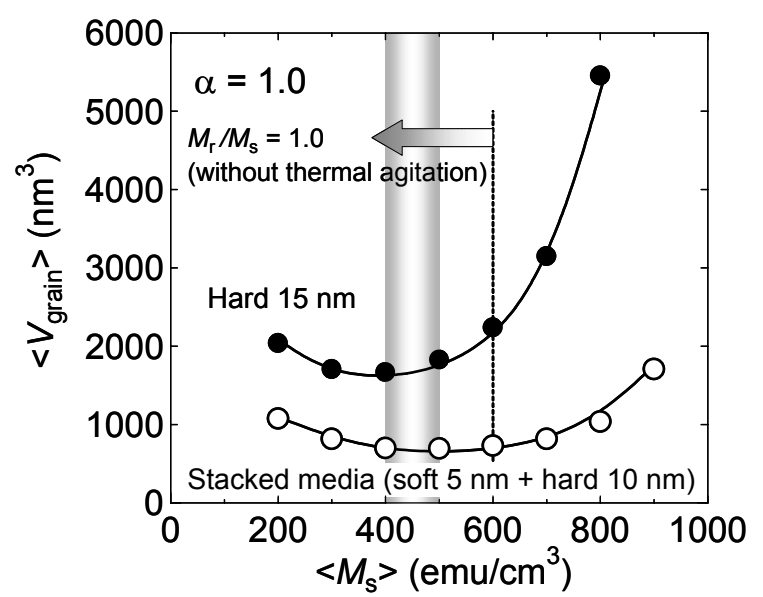

Fig. 5 Change in grain volume for $H_{\mathrm{s}}=16 \mathrm{kOe}$ and $\Delta E / \mathrm{kT}=60$ as a function of the saturation magnetization.

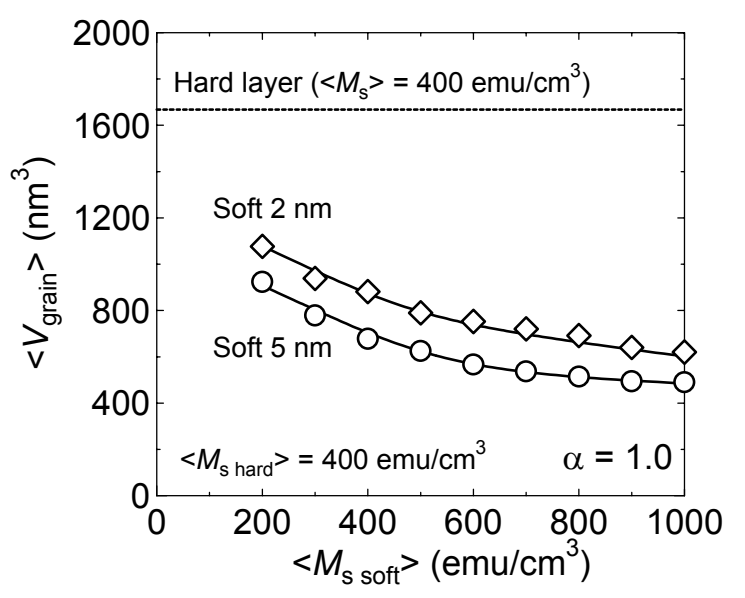

Fig. 6 Change in grain volume for $H_{\mathrm{s}}=16 \mathrm{kOe}$ and $\Delta E / \mathrm{kT}=60$ as a function of the saturation magnetization of the soft layer. 
結果をそれぞれ示しており，< $M_{\mathrm{s}}>$ が $400 \mathrm{emu} / \mathrm{cm}^{3}$ の単層 媒体におけるく $V_{\text {grain }}>$ も比較のため示している.

$<M_{\mathrm{s}}^{\text {soft }}>$ が大きくなるほど< $V_{\text {grain }}>$ は低下している. ソフ 卜層の膜厚が $2 \mathrm{~nm}$ の場合でも, $<M_{\mathrm{s}}$ soft>=1000 emu/cm ${ }^{3}$ （充填率 $70 \%$ Co にほぼ相当）の< $V_{\text {grain }}>$ は約 $620 \mathrm{~nm}^{3}$ まで低下しており，上下両層の $<M_{\mathrm{s}}>$ が $400 \mathrm{emu} / \mathrm{cm}^{3}$ の場 合よりも，さらに低減できることがわかる．この< $V_{\text {grain }}>$ は, 単層媒体に比較して 2.7 分の 1 の小さな值である.

以上のことから, ソフト層の膜厚を $2 \mathrm{~nm}$ と薄く設定し ても, 純 Co を用いたグラニュラ膜相当まで $<M_{\mathrm{s}}^{\text {soft }}>$ を増加 させることで, < $V_{\text {grain }}>$ は単層媒体の約 $1 / 3$ まで小さくする ことができることが明らかとなった。

\section{3.実験による検証}

\section{1 実験方法}

試料は ANELVA 社製 UHV-DC，RF マグネトロンスパ ッタリング装置によって直径 $65 \mathrm{~mm}$ のハードディスク用 ガラス基板に製膜した。装置の到達真空度は $10^{-7} \mathrm{~Pa}$ であ る. シード層は, 基板側より, $\mathrm{Ta}, \mathrm{Pt}, \mathrm{Ru}$ 層をそれぞれ 5 , 10，20 nm 形成したものを用いた．八ード層には計算結果 に合わせ $<M_{\mathrm{s}}>$ を $400 \mathrm{emu} / \mathrm{cm}^{3}$ 程度に調整した $(\mathrm{Co}-\mathrm{Pt})-\mathrm{SiO}_{2}$ グラニュラ層を用い, 膜厚は $9 \mathrm{~nm}$ とした.

ソフト層には $<M_{\mathrm{s}}>$ が大きな $\mathrm{Co}^{-} \mathrm{SiO}_{2}$ を $2 \mathrm{~nm}$ 用いた. なお, 両層に添加した $\mathrm{SiO}_{2}$ 量は, 磁気特性の評価から粒子の磁気 的分離度が最も高くなる添加量に調節しており, 電子顕微 鏡による組織観察によって, 概ね個々の粒子がアモルファ ス層によって分離されたグラニュラ構造を有することを確 認している. ここで, $2 \mathrm{~nm} の \mathrm{Co}^{-} \mathrm{SiO}_{2}$ ソフト層をスタッ クした媒体の $<M_{\mathrm{s}}>$ は $500 \mathrm{emu} / \mathrm{cm}^{3}$ 程度であり, $\mathrm{Co}-\mathrm{SiO}_{2}$ ソフト層のみの $<M_{\mathrm{s}}>$ は約 $950 \mathrm{emu} / \mathrm{cm}^{3}$ に相当する. 界面 の交換結合力を制御する層としては $\mathrm{Pt}^{8}$ に $\mathrm{SiO}_{2}$ を添加した $\mathrm{Pt}-\mathrm{SiO}_{2}$ 用い, 膜厚を $0 \sim 3 \mathrm{~nm}$ まで変化させることで結合 力を制御した。製膜は全て室温にて行なった。磁化曲線及 び残留磁化曲線の測定は, VSM を用いて $10 \mathrm{Oe} / \mathrm{s}$ 台の磁 界変化速度において測定した。一部の実験では，パルス磁 界を用いて〜 $10^{8} \mathrm{Oe} / \mathrm{s}$ の磁界変化速度における残留磁化曲 線も評価した。

記録再生特性の評価には, $\mathrm{CoZrNb}$ 軟磁性層（膜厚 200 $\mathrm{nm}$ )を裏打ち層としてガラス基板とシード層の間に形成し た媒体を用いた。実験は日立ハイテク製スピンスタンド （RH 4160E）を用いた。記録にはマージ型単磁極ヘッド を用いており, 記録へッドの主磁極材料の飽和磁束密度は $2.4 \mathrm{~T}$, ライトコア幅は $180 \mathrm{~nm}$, 再生へッドについては, リードコア幅が $140 \mathrm{~nm}$, シールドギャップ長が $55 \mathrm{~nm}$ の GMR ヘッドを用いている. 線速度は $10.16 \mathrm{~m} / \mathrm{s}$ とした. 再 生出力はトラック 1 周分の平均の振幅 (0 to peak) とし, 媒体ノイズは各記録密度の再生波形をスペクトラムアナラ イザに取り込み, 0 160 MHz までのノイズ電力量を積分し て求めた。ここで，媒体以外から生ずるノイズは差し引い てある. 信号対雑音比 $S N_{m} R$ 值はこれら再生出力と媒体ノ
イズより求めた。

\section{2 残留保磁力の変化}

Fig. 7 には, 界面交換結合制御層 $\left(\mathrm{Pt}-\mathrm{SiO}_{2}\right.$ 層) $0.0 \mathrm{~nm}$ から $3.0 \mathrm{~nm}$ まで変化させた場合の磁化曲線の変化の様子 を示す. 図には磁化曲線と共に残留磁化曲線を白丸で示し てあり, $0.0 \mathrm{~nm}$ についてはハード層のみの場合の結果も示 した.

ハード層に直接ソフト層を付与した場合，保磁力は約 30\%程度低減していた。ここに $\mathrm{Pt}^{-} \mathrm{SiO}_{2}$ を挿入すると保磁 力はさらに低下し, $1.5 \mathrm{~nm}$ で極小となっていた.さらに $2.0 \mathrm{~nm}$ と厚くすると, 磁化曲線上には段差が観察され, 磁 化曲線と残留磁化曲線に大きな差が現れるようになる。こ れは, ソフト層のみが可逆的に反転するスピンフロップ状 態である. $3.0 \mathrm{~nm}$ ではソフト層も非可逆的に反転し, 磁気 的な結合力が非常に弱くなっている. これらの界面結合力 の低下による磁化機構の段階的な変化は, 理論的な予測と 良く一致していることがわかる，ここで，0２ $\mathrm{nm}$ に及ぶ 膜厚領域にわたり上下層の磁化の交換結合力が徐々に低下 して行く理由は，Ptの分極の影響であると考えられ， Pt の分極厚みともほぼ一致する ${ }^{8)}$. なお，Fig. 7 において, $\mathrm{Pt}^{-\mathrm{SiO}_{2}} 3 \mathrm{~nm}$ まで厚くしてもソフト層の磁化が垂直方向 を向いている理由は, $\mathrm{Pt}-\mathrm{SiO}_{2}$ 層と $\mathrm{Co}-\mathrm{SiO}_{2}$ 層の間に誘導 される界面異方性が関係しているものと推察される。 $\mathrm{Co}-\mathrm{SiO}_{2}$ 層との界面異方性が小さな $\mathrm{NiFeCr}-\mathrm{SiO}_{2}$ 等を界面 結合制御層に用いた場合 7)には，スピンフロップが現れる 膜厚以上に界面制御層を厚くすると，角型比は低下する.

Table1 には, これらのサンプルの残留保磁力 $H_{\mathrm{r}}$ と, パ ルス磁界を用いて高速な磁界変化速度（～108 $\mathrm{Oe} / \mathrm{s} ）$ で評 価した残留保磁力 $H_{\mathrm{r}} \mathrm{P}$ の值を示した. $H_{\mathrm{r}} \mathrm{P}$ と $H_{\mathrm{r}}$ の比は, 1.5 $\mathrm{nm}$ の $\mathrm{Pt}_{-} \mathrm{SiO}_{2}$ 層の挿入により低下するが, $\mathrm{Pt}_{-}-\mathrm{SiO}_{2}$ 層が 2.0 $\mathrm{nm}$ になると急激に増加している.

$\mathrm{Pt}-\mathrm{SiO}_{2}$ 層が $2.0 \mathrm{~nm}$ の媒体では, ハード層とソフト層の
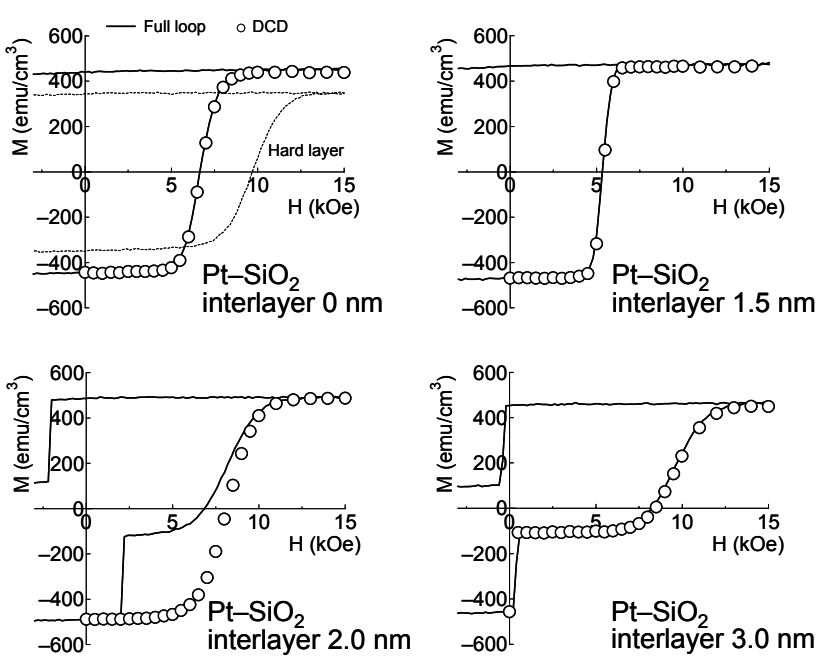

Fig. 7 Hysteresis loops for stacked media with various $\mathrm{Pt}-\mathrm{SiO}_{2}$ interlayer thicknesses. 
結合力が弱くなりスピンフロップが現れていることから， 残留保磁力を決める磁化反転単位はハード層によりほぼ決 定されつつあると考えられる。したがって，同媒体におけ る $H_{\mathrm{r}} \mathrm{P} / H_{\mathrm{r}}$ の増加は, 媒体の熱安定性が急激に劣化している ことを示している ${ }^{9)}$.

一方, $1.5 \mathrm{~nm}$ の $\mathrm{Pt}-\mathrm{SiO}_{2}$ 層の挿入により $H_{\mathrm{r}} \mathrm{P} / H_{\mathrm{r}}$ は低下 しており，媒体の熱安定性が良くなっているようにも見え る。しかし, 同媒体では, ソフト層の磁化が先に反転を開 始することで $H_{\mathrm{r}}$ が低下し, 磁化反転機構が大きく変化して いると考えられることから， $H_{\mathrm{r}}^{\mathrm{P}} / H_{\mathrm{r}}$ の変化から熱安定性を 単純に議論できない. Fig. 2 に示したエネルギー計算の結果, 界面の結合力が低下寸ると磁気エネルギーのポテンシャル 曲線が一斉回転型から徐々に変化していき, エネルギー障 壁に変化が無くても， $H_{\mathrm{r}} \mathrm{P} / H_{\mathrm{r}}$ が小さくなることを確認して いる.したがって, $1.5 \mathrm{~nm}$ の $\mathrm{Pt}-\mathrm{SiO}_{2}$ 層の挿入による $H_{\mathrm{r}} \mathrm{P} / H_{\mathrm{r}}$ の低下は磁化機構の変化に起因するものであり, 媒体の熱 安定性はほとんど変化していないことを示唆しているが, 定量的な議論は今後の課題である.

Fig. 8 には，A〜C の種々の成膜プロセス条件で作製し た場合の, $\mathrm{Pt}-\mathrm{SiO}_{2}$ 膜厚に対する残留保磁力の変化率を示 した.ここで, Fig. 7 の結果は，B に対応する. 成膜条件 の違いによらず $H_{\mathrm{r}}$ は $\mathrm{Pt}-\mathrm{SiO}_{2}$ が $1.5 \mathrm{~nm}$ で極小となってい た.また, $2.0 \mathrm{~nm}$ 近辺の領域ではいずれもスピンフロップ 状態となっていた.

この内, 界面結合の低下による $H_{\mathrm{r}}$ の低下率が最も大きい

Table1 Values of $H_{\mathrm{r},} H_{\mathrm{r}}^{\mathrm{P}}$ and $H_{\mathrm{r}}^{\mathrm{P}} / H_{\mathrm{r}}$ for hard/soft-stacked media with various $\mathrm{PtSiO}_{2}$ layer thicknesses.

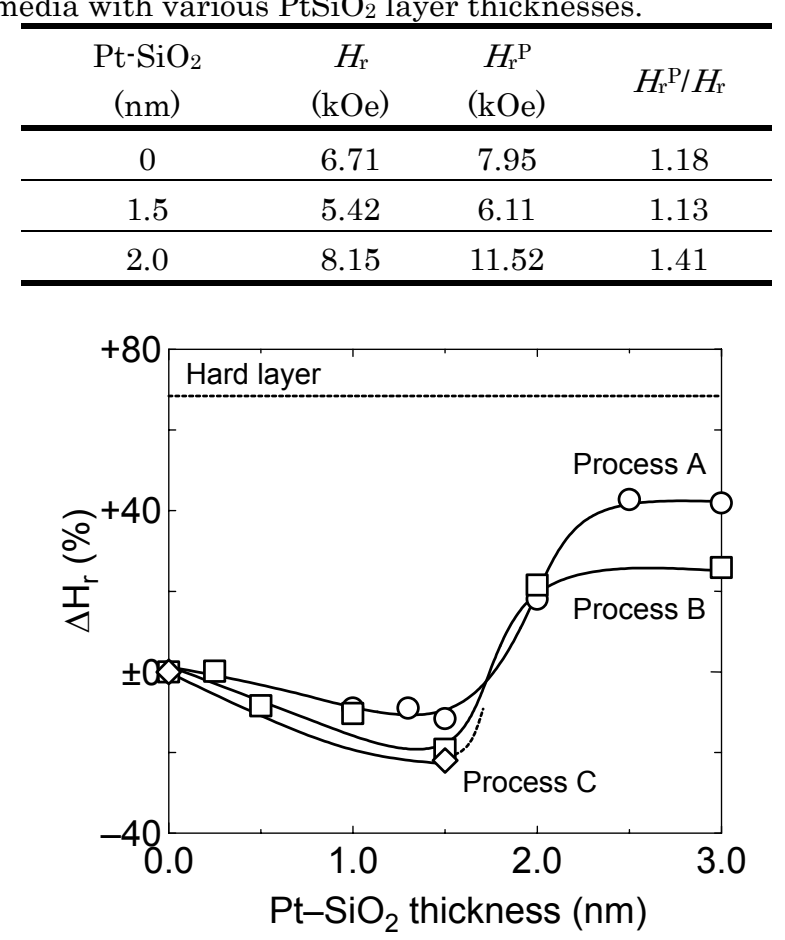

Fig. 8 Interlayer thickness dependences for the reduction ratio of the remanence coercivity.
プロセス C では, ソフト層を直接スタックした媒体で $5.9 \mathrm{kOe}$ だった $H_{\mathrm{r}}$ が $4.6 \mathrm{kOe}$ まで低下しており， $H_{\mathrm{r}}$ の低下 率は約 $22 \%$ あった。一方, 実験に用いたソフト層および ハード層の物性值を用いて, 先に述べたような磁気エネル ギーの計算を行った結果, 界面結合の低下による $H_{\mathrm{r}}$ の低下 率は $43 \%$ と算出された. 実験で得られている $H_{\mathrm{r}}$ の低下率 は, この約 $1 / 2$ の值である. 計算では, $H_{\mathrm{r}}$ の低下率を $H_{\mathrm{r}}$ の極小值 (Fig. 2 参照) から求めており, わずかな Jの分 散により $H_{\mathrm{r}}$ の低下率は小さくなる. したがって, $H_{\mathrm{r}}$ の低 下率が計算值よりも小さく抑えられている原因の一つは, 界面結合力の分散であると推測される.

\section{3 記録再生特性}

Fig. 9 に高記録密度（500 kFCI）の上に低記録密度（70 $\mathrm{kFCI}$ )を上書きした場合のオーバーライトを, 記録電流に 対して示す. 図中には, プロセス $\mathrm{C}$ で成膜した $\mathrm{Pt}-\mathrm{SiO}_{2}$ 層 が 0.0 と $1.5 \mathrm{~nm}$ の 2 つの媒体と, 総厚が同じ単層媒体の結 果を示してある. $\mathrm{Co}^{-} \mathrm{SiO}_{2}(2 \mathrm{~nm})$ をスタックすることによ り飽和記録特性が向上し, さらに界面結合力を低下させる ことで効果的にオーバーライトが改善されていることがわ かる.

Figs. 10，11 には，これらの媒体の規格化した出力電圧 および $S N_{m} R$ を，線記録密度に対してそれぞれ示した。 ッドの記録電流は全て $50 \mathrm{~mA}_{0-\mathrm{p}}$ で一定とした.

記録分解能 $D_{50}$ は，単層媒体では $307 \mathrm{kFCI}$ であるが， ソフト層の付与により $580 \mathrm{kFCI}$ 近くまで向上し, さらに 界面の交換結合力を低下させることで $630 \mathrm{kFCI}$ 近くまで 向上していた．また，ソフト層のスタック化によるオーバ 一ライト特性の改善が主因と考えられるが， $S N_{\mathrm{m}} R$ の顕著 な改善が認められた.さらに $S N_{\mathrm{m}} R$ は界面結合力を低下さ せることにより僅かに向上していた。

ここで, 界面結合の低下による $S N_{m} R$ の向上は, 記録分 解能の向上, オーバーライト特性の向上の他に, 保磁力の 低下による実効的なトラック幅の増加が要因として作用し ていると考えられる。ただし，種々の条件で作製した媒体 について，実効的なトラック幅が同じになるように記録電 流を調整して測定したところ, $D_{50}, S N_{\mathrm{m}} R$ 等の信号品質は, 界面結合力の低減により若干良くなることはあっても，劣 化することは全く無かった。これらのことは, ソフト層の スタック化ならびに界面結合力の低下が，信号品質を劣化 させることなく飽和記録特性を向上させることを示してい る.

一方，実験を行った全ての媒体は，低記録密度時の磁化 の減衰は全く観察されていない。これは，評価したいずれ の媒体も VSM の時間スケールの角型比がほぼ 1 であるこ とに対応しており，信号の時間減衰の評価から熱安定性の 変化を議論には至っていない. 


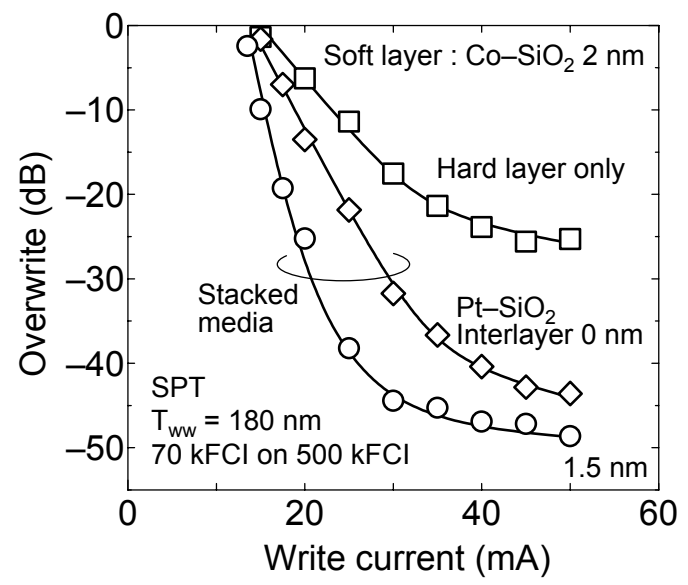

Fig. 9 Overwrite profiles for a hard/soft-stacked medium and a hard layer medium.

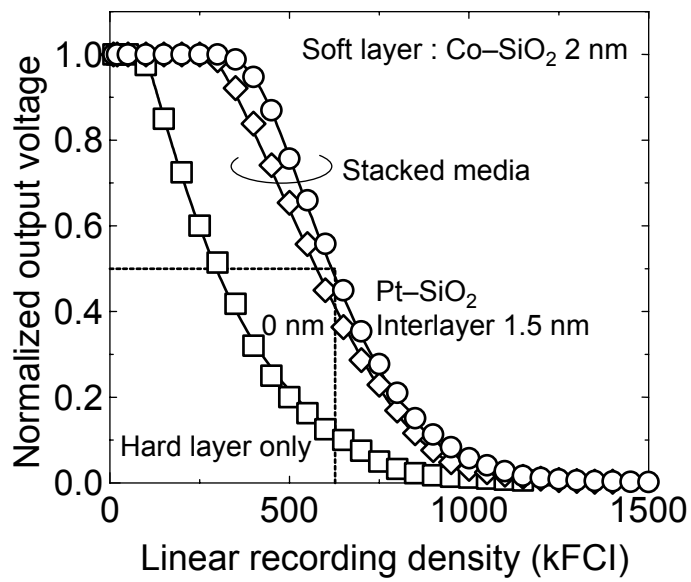

Fig. 10 Roll-off profiles for a hard/soft-stacked medium and a hard layer medium.

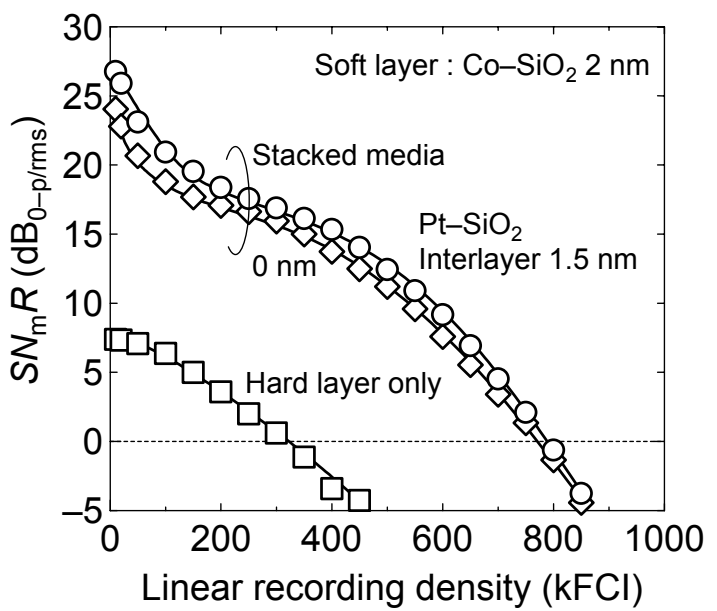

Fig. 11 Signal-to-noise ratio $S N_{\mathrm{m}} R$ for a hard/soft-stacked medium and a (Co-Pt)- $\mathrm{SiO}_{2}$ medium as a function of the linear recording density.

\section{4. まとめ}

薄いソフト層を有するグラニュラ型のスタック媒体を想定し, 膜厚, 飽和磁化, ハード層とソフト層界面の交換結合の強 さと，媒体のスイッチング磁界及び熱安定性の関係を議論
した.

磁気エネルギー計算の結果，ソフト層の飽和磁化を大き くし, 且つ, 界面交換結合を適切な值に低減させることで, $2 \mathrm{~nm}$ という薄いソフト層膜厚においても, 飽和記録特性と 熱安定性を維持しながら，八ード層単層に比べて粒子体積 を $1 / 3$ 近くまで低減できることが明らかとなった.

飽和磁化の大きな $\mathrm{Co}^{-} \mathrm{SiO}_{2}$ をソフト層に採用し, $\mathrm{Pt}-\mathrm{SiO}_{2}$ 層を界面結合力制御層として用いた実験の結果，界面の交 換結合を低減していくことで，理論的に予測される段階的

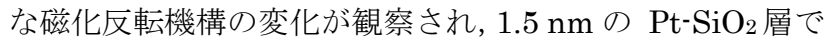
残留保磁力は最大 $22 \%$ 低下した。 また, 記録再生特性の評 価の結果, ソフト層のスタック化ならびに界面結合力の低 下が，信号品質を劣化させることなく飽和記録特性を向上 させることが明らかとなった。

スタック媒体の持つ利点を最大限に活かした媒体開発の ためには, 残留保磁力の低下率と磁化機構との関係の明確 化，ならびに，熱安定性に関する定量的な議論をさらに進 めていくことが必要である.

謝辞 本研究の一部は, 文部科学省平成 18 年度科学技術試 験研究(RR2002, 超小型大容量ハードディスクの開発)の支 援により行われた。ここに深謝する.

\section{References}

1) Y. Inaba, T. Shimatsu, O. Kitakami, H. Sato, T. Oikawa, H. Muraoka, H. Aoi, and Y. Nakamura: J. Magn. Soc. Jpn., 29, pp. 239-242 (2005).

2) Y. Inaba, T. Shimatsu, O. Kitakami, H. Sato, T. Oikawa, H. Muraoka, H. Aoi, and Y. Nakamura: IEEE Trans. Magn., 41, pp. 3136-3138 (2005).

3) Y. Inaba, T. Shimatsu, O. Kitakami, H. Muraoka, H. Aoi, and Y.Nakamura: Digest of 29th Annual Conference on Magnetics in Jpn., 21pA-15 (2005).

4) R. H. Victora and X. Shen: IEEE Trans. Magn., 41, pp. 537-542 (2005).

5) K. Nakamoto, and H. N. Bertram: J. Magn. Soc. Jpn., 26, pp. 79-85 (2002)

6) J. Hokkyo. H. Hokkyo, H. Matsutera, K. Yamada, and T. Osaka: Digest of $23^{\text {th }}$ Annual Conference on Magnetics in Jpn., $5 \mathrm{aB}-1$ (1999)

7) T. Shimatsu, Y. Inaba, S. Watanabe, O. Kitakami, S. Okamoto, H. Aoi, H. Muraoka, and Y. Nakamura : IEEE Trans. Magn., $43(2007)$ in press. [Abstracts of $10^{\text {th }}$ Joint MMM/Intermag Conference, FX-02, Baltimore, Jan. 7-11 (2007).]

8) S. Okamoto, O. Kitakami, N. Kikuchi, T. Miyazaki, Y. Shimada, and Y. K. Takahashi: Phys. Rev. B, 67, 094422 (2003).

9) T. Shimatsu, H. Uwazami, H. Muraoka, and Y. Nakamura: J. Magn. Soc. Jpn., 26, pp. 109-117 (2002).

2006 年10月 20 日受理，2007年 3 月 19 日採録 